\title{
Orfebrería portuguesa en España. Piezas inéditas de la diócesis de Ciudad Rodrigo
}

\author{
Manuel Pérez Hernández - Eduardo Azofra \\ Universidad de Salamanca
}

\begin{abstract}
RESUMEN. Este trabajo propone una aproximación a las relaciones artísticas entre España y Portugal, centrada en el campo de la platería religiosa de la diócesis de Ciudad Rodrigo, lugar que, por su proximidad a la frontera se convirtió en centro de recepción de piezas realizadas a ambos lados de "la Raya"; en todo caso pensamos que estas relaciones constituyen una línea de investigación sobre la que se debe seguir profundizando. Cronológicamente las piezas van de fines del siglo XVI a principios del XIX, destacando las procedentes de Oporto. En el trabajo, además del análisis estilístico, o su relación con obras conservadas en museos del vecino país, se incide en la serie de factores que pueden explicar su llegada, unos de índole político, estamos en un momento de estabilidad, y otros internos, como el favorable ambiente cultural que en ese momento se respiraba en Ciudad Rodrigo.

Palabras clave: Platería, orfebrería religiosa, ajuar litúrgico, Ciudad Rodrigo, Portugal. Siglos XVI- XIX.

ABSTRACT. This paper proposes an approach to the artistic relations between Spain and Portugal, focusing on the field of religious silverware in the diocese of Ciudad Rodrigo, a place which, with its proximity to the border, became a reception centre for pieces made on both sides of the "raya". In any case we consider that these relations constitute a line of research which should be dealt with more in depth. Chronologically, the pieces date from the $16^{\text {th }}$ to the beginning of the $19^{\text {th }}$ centuries, with those from Porto being the most outstanding. In this paper, besides a stylistic analysis, and an analysis of their relationship to works preserved in the museums of Portugal, emphasis is placed on the series of factors that can explain how they came to be in Ciudad Rodrigo, some of a political nature, it being a time of stability, and other internal factors such as the favourable cultural climate prevailing there at that time.

Key Words: Silverware, religious silverware, liturgical objects, Ciudad Rodrigo, Portugal, $16^{\text {th }}-19^{\text {th }}$ centuries.
\end{abstract}

En los últimos años, a partir de los periódicos encuentros entre historiadores lusos y españoles, de los proyectos desarrollados conjuntamente con motivo de la celebración de acontecimientos como el V Centenario del Descubrimiento de América o de la firma del Tratado de Tordesillas o de los estudios aparecidos en diferentes publicaciones, se ha ido abriendo una línea de investigación que va poniendo de manifiesto, si bien creemos que todavía queda mucho por hacer en este campo, las relaciones y los vínculos artísticos entre los dos países de la Península Ibérica, la participación de artistas de un lado de la frontera en la ejecución de obras del estado vecino o, entre otros aspectos, cómo esos contactos artísticos se convirtieron en una de las vías más frecuentes para el traspaso y la difusión a un país de los modelos acuñados en el otro.
En el caso de la platería, donde poco a poco van apareciendo trabajos publicados al respecto $^{1}$, y en concreto en el tema de la orfebrería de la diócesis civitatense, que es el que a nosotros nos atañe en este artículo, ya expusi-

\section{-}

${ }^{1}$ A. RODRIGUes MourinHo, "Noticia de plateros zamoranos en la primera mitad del siglo XVIII en la catedral de Miranda de Douro (Portugal)", en Homenaje a Juan José Martín González, Valladolid, 1995, pp. 675-678; J. FILGUEIRA VALVERDE, "Orfebrería portuguesa en Galicia. Tres cruces del Museo de Pontevedra", en Homenaje a Juan José Martín González, Valladolid, 1995, pp. 663-668; M. PÉREZ HERNÁNDEZ, "Relaciones entre la platería salmantina y portuguesa", Brigantia. Revista de Cultura, XVI (1/2), Bragança, 1996, pp. 55-64; J. NAVARRO TALEGÓN, "Artistas zamoranos en la diócesis de Bragança-Miranda", Actas del Congreso "450 años de la Diócesis Bragança-Miranda", Bragança, 1996, pp. 589-617; Mà. J. REDONDO CANTERA, "Desventuras de artistas portugueses en tierra extraña: algunos ejemplos en Castilla y León durante la Edad Moderna", Artis, 2, 2003, pp. 95-105 (96-100). 
mos en su momento el origen portugués del cáliz-custodia del Tesoro Sagrado de la seo rodericense, hoy en el Museo Diocesano y Catedralicio de Ciudad Rodrigo ${ }^{2}$, una pieza de excepcional calidad y que hasta hace bien poco estaba considerada como la única de la diócesis mirobrigense labrada en la vecina Portugal, circunstancia corregida recientemente, pues esa misma procedencia se ha comprobado para otros tres cálices que, también del tesoro de la catedral, se exhiben en la actualidad en las vitrinas del citado museo ${ }^{3}$.

En el presente trabajo a esas cuatro piezas se añaden quince más, todas ellas inéditas, para un total de diecinueve obras que, a excepción de una cruz procesional, el resto forman parte del ajuar litúrgico, destacando por su número los cálices, en concreto catorce, a los que se deben sumar dos custodias y otros tantos copones, y que abarcan cronológicamente un amplio periodo temporal que se extiende desde finales del siglo XVI o comienzos del XVII hasta los primeros años del XIX. Este número de ejemplares supone algo más del $2 \%$ de todas las piezas existentes en la diócesis de Ciudad Rodrigo, superando, si bien en algunos casos

-

2 M. F. Sendín Calabuig, Ciudad Rodrigo, León, 1991 (1973), p. 50; M. SEGUí GONZÁLEZ, La platería en Ciudad Rodrigo. Trabajo inédito, premio Julián Sánchez “el Charro" 1988 (Archivo Municipal de Ciudad Rodrigo); J. R. NiETo GonZÁLEZ, "La Catedral de Ciudad Rodrigo", en AA. VV., Las Catedrales de Castilla y León, León, 1992, p. 82; E. AZOFRA Y P. SAN ROMÁN, "Aportación a la platería de la Diócesis de Ciudad Rodrigo. Diez custodias de mano renacentistas", Salamanca. Revista de Estudios, 38, 1997. pp. 197-219 (216-218); J. C. BRASAS EGIDO, ficha $\mathrm{n}^{\circ} 138$ del Catálogo de la Exposición "La ciudad de Seis Pisos" (El Burgo de Osma), Madrid, 1997, pp. 246-247; J. R. Nieto GonzÁlez, Ciudad Rodrigo. Análisis del Patrimonio Artístico, Salamanca, 1998, pp. 76-78; M. PÉREZ HERNÁNDEZ Y E. AZOFRA, "Cálices-custodias portugueses", Brigantia. Revista de Cultura, XIX (1/2), Bragança, 1999, pp. 4752; E. AzOFRA, ficha $\mathrm{n}^{\mathrm{o}} 31 \mathrm{del}$ Catálogo de la Exposición "La platería en la época de los Austrias Mayores en Castilla y León” (Valladolid), Valladolid, 1999, pp. 364-367; IDEM, "Aportaciones a la platería de la Diócesis de Ciudad Rodrigo. Las custodias del Campo de Argañán", Catálogo de la Exposición Itinerante "Gólgota. Drama de Pasión y Pascua. Pasión por una tierra", Salamanca, 2004, pp. 2328 (25-26); E. AZOFRA Y M. PÉREZ HERNÁNDEZ, ficha $\mathrm{n}^{\circ}$ 112 del Catálogo de la Exposición "Kyrios" (Ciudad Rodrigo), Salamanca, 2006, pp. 263-264; M. PÉREZ HERNÁNDEZ, "Las artes del objeto. La platería en la catedral de Ciudad Rodrigo", en E. AzOFRA (Ed.), La Catedral de Ciudad Rodrigo a través de los siglos. Visiones y Revisiones, Salamanca, 2006, pp. 363-410 (386).

3 M. PÉREZ HERnÁNDEZ, “Las artes del objeto...”, en E. Azofra (Ed.), La Catedral de Ciudad Rodrigo..., pp. 387388 . sólo por una obra, a todos los centros plateriles nacionales representados (de Córdoba se conservan dieciocho piezas, de Madrid quince o de Barcelona catorce). Obviamente, de esa relación excluimos tanto a los talleres mirobrigenses como salmantinos, concretamente la aportación de estos últimos al total de piezas conservadas supera con creces el $50 \%$.

La circunstancia referida con anterioridad, que por sí sola ya resulta bastante significativa y que sin duda alguna sólo es explicable por la condición de frontera de la diócesis de Ciudad Rodrigo con la vecina Portugal, y que además pone de manifiesto que la relación, cuanto menos artística, entre Miróbriga y los talleres de allende de la "raya" se mantuvo a lo largo del tiempo a pesar de los diferentes y continuos conflictos bélicos que se produjeron entre los países de la Península Ibérica en esos siglos ${ }^{4}$, hecho sobre el que volveremos más tarde, adquiere un valor aún más relevante cuando se comprueba que casi todas las piezas portuguesas que nos han llegado, exactamente quince de las diecinueve, fueron labradas en un periodo muy concreto, el que transcurre aproximadamente entre 1770 y 1810 , y que de éstas once de ellas (incluso hemos dejado fuera la existente en el museo catedralicio y diocesano debido a la "lejanía" a la que se encuentra Ciudad Rodrigo de Portugal) se localizan en poblaciones lindantes con la "raya" (La Bouza, Fuentes de Oñoro, Alberguería de Argañán) o separadas de la frontera apenas diez kilómetros (Lumbrales, San

\footnotetext{
-

${ }^{4}$ Sobre el carácter fronterizo de Ciudad Rodrigo y los avatares y las consecuencias sufridos tanto por la ciudad como por la diócesis a lo largo de los principales enfrentamientos bélicos acaecidos entre España y Portugal (Guerra de la Independencia de Portugal, de mediados del siglo XVII, Guerra de Sucesión Española, de principios del XVIII, y Guerra de la Independencia Española a comienzos del XIX) existen numerosas referencias bibliográficas, algunas de ellas ya clásicas, por lo que no es nuestra intención extendernos sobre este particular, cuando además casi todas ellas han sido recogidas en el estudio de M. PÉREZ HERNÁNDEZ, "Las artes del objeto ...", en E. AZOFRA (Ed.), La Catedral de Ciudad Rodrigo ... Por otra parte, que las relaciones entre los vecinos de ambos lados de la raya debió de ser una constante histórica, incluso en los momentos de mayor tensión, se pone de manifiesto en el hecho de que uno de los cálices portugueses conservados en Alberguería de Argañán fuese adquirido en plena Guerra de la Independencia Española, tras los sitios de 1810, en concreto en 1811. Archivo Diocesano de Ciudad Rodrigo (A.D.C.R.). Archivo parroquial de Alberguería de Argañán. Libro de cuentas de fábrica, 1746-1789 (Sig. 159). F. $232 \mathrm{v}^{\mathrm{o}}$. Cuentas del año 1811. Descargo de 585 reales que tuvo de coste un cáliz de plata con su patena y cucharita.
} 
Felices de los Gallegos, Villar de Ciervo, Villar de la Yegua, Puebla de Azaba y Castillejo de Azaba), detalle que también creemos debe de ser destacado. Además, en este caso, esas quince piezas vienen a significar casi el $10 \%$ de las obras localizadas de esos años en la diócesis civitatense, convirtiéndose así la orfebrería portuguesa en el segundo centro plateril, después, por supuesto, de Salamanca; sobrepasando en número y en calidad (sirvan como ejemplo de lo que decimos la custodia de Villar de Ciervo -Lámina 8,1- o los cálices de Lumbrales, San Felices de los Gallegos, convento de El Zarzoso y Fuentes de Oñoro -Lámina 7, 1 y 2, Lámina 6, 1 y 3-, respectivamente), a los labrados por esos mismo años en los talleres de la ciudad del Águeda, y ello a pesar de la revitalización experimentada por la platería de Ciudad Rodrigo en esos años, último tercio del siglo XVIII y primero de la centuria siguiente, un periodo que hemos dado en llamar la segunda etapa de esplendor de la platería mirobrigense y cuyo máximo exponente será José Genaro García, un platero que tanto estructural como decorativamente evolucionó desde un rococó final, muy avanzado y ya casi agotado, hasta un lenguaje propio de un incipiente neoclasicismo ${ }^{5}$.

A nuestro entender una de las claves, quizás la más importante, que puede explicar ese auge de la orfebrería rodericense sea la recuperación económica que vivió Ciudad Rodrigo y su territorio en ese limitado espacio temporal que hemos señalado ${ }^{6}$. Una situación,

${ }^{5}$ Se trata del periodo del que más piezas se han conservado de los talleres mirobrigenses. E. AzOFRA, "Aportaciones... Las custodias del Campo de Argañán", Catálogo ... "Gólgota. Drama de Pasión y Pascua .."., p. 28; IDEM, "Aportaciones a la platería de la Diócesis de Ciudad Rodrigo. Varias piezas inéditas punzonadas durante las contrastías de los plateros Rodrigo de Salazar (1577-1603) y Pedro de Salazar (1604-1620)", Estudios de Platería. San Eloy 2004, Murcia, 2004, pp. 81-97 (82); E. AZOFRA Y M. PÉREZ HERNÁNDEZ, "Aportaciones a la orfebrería de la diócesis de Ciudad Rodrigo: el platero José Genaro García”, Estudios de Platería. San Eloy 2005, Murcia, 2005, pp. 67-90.

${ }^{6}$ Reflejo de esa recuperación económica, y de la llegada a Ciudad Rodrigo del proyectismo ilustrado, será la creación de diferentes fábricas de textiles, curtidos, loza, harina, aceite, vino, jabón, cordobanes, etc., que aparecen registradas en El Libro del Bastón, fuente básica para el conocimiento de la situación económica del momento. Esta fuente puede consultarse en Departamento de El Bastón de L. M. N. y M. L. Ciudad de Ciudad Rodrigo. Año de 1770, con prólogo de Constancio Bernaldo de Quirós, Publicación del Ministerio de Trabajo y Previsión, Junta de Colonización Interior, Imprenta Helénica, Madrid, 1929. Reeditado en Salamanca. Revista Provincial de Estudios, $\mathrm{n}^{\circ} 2$ y 3, sin duda muy favorable, que no sólo es apreciable en el ámbito de la platería (donde, por otra parte, no se debe pasar por alto que aproximadamente una tercera parte de las obras localizadas en esta diócesis fueron labradas a lo largo de esos años), sino que también repercutió de forma muy considerable en otros campos artísticos, sobre todo en el arquitectónico, en el que los desembolsos económicos además son todavía más cuantiosos ${ }^{7}$. Ese momento de bonanza irá acompañado con un interesante resurgir de la actividad cultural e intelectual en Ciudad Rodrigo y tendrá su máxima expresión en la creación de la Sociedad Económica de Amigos del País de Ciudad Rodrigo, cuyos estatutos fueron aprobados por real cédula del 27 de noviembre

1982, pp. 228-293 y 136-233. Algunas notas sobre esta fuente en E. GARCÍA ZARZA, "Comentarios sobre el Libro del Departamento de El Bastón, de L. M. N. y M. L. Ciudad de Ciudad Rodrigo", Salamanca. Revista Provincial de Estudios, no 4, 1982, pp. 159-176. La otra fuente primordial para el conocimiento de Ciudad Rodrigo a mediados del siglo XVIII es el Catastro de Ensenada, estudiado por A. Cabo Alonso, Ciudad Rodrigo. 1750. Según las Respuestas Generales del Catastro de Ensenada, Madrid, 1990.

${ }^{7}$ Un buen estado de la cuestión sobre el proceso constructivo llevado a cabo en Ciudad Rodrigo a lo largo de todo el siglo XVIII puede encontrarse en J. R. NIETO GONZÁLEZ, Ciudad Rodrigo. Análisis del Patrimonio Artístico, Salamanca, 1998, pp. 159-162. En páginas siguientes, 162-198, se analizan ya de forma pormenorizada las principales obras levantadas durante esa centuria. Sobre las obras efectuadas en las últimas cuatro décadas del siglo XVIII que fueron trazadas, y en ocasiones dirigidas, por Juan de Sagarbinaga a partir de diferentes lenguajes del clasicismo, vid. también E. AzOFRA, El arquitecto Juan de Sagarbinaga (17101797), Tesis Doctoral inédita, Salamanca, 2003, pp. 164175; IDEM, El seminario conciliar de San Cayetano de Ciudad Rodrigo (Salamanca), obra del arquitecto Juan de Sagarbinaga en tiempos de monseñor Cayetano Cuadrillero y Mota, Salamanca, 2004; IDEM, "La Plaza Mayor de Ciudad Rodrigo", Plazas con encanto de la provincia de Salamanca, Salamanca, 2005, pp. 74-83; IDEM,"Ventura Moiños", en AA. VV., Diccionario Biográfico Español de la Real Academia de la Historia (en prensa). Y en el ámbito diocesano también se llevó a cabo una importante renovación de su patrimonio edilicio en esas fechas. Sirvan de ejemplo las transformaciones realizadas en las iglesias de Robleda, del convento de la Casa Baja en El Má́llo, Lumbrales, Villar del Ciervo, Villar de la Yegua, Gallegos de Argañán, Cabrillas, El Bodón o en la casa-palacio de Sepúlveda de Yeltes, entre otros, o los templos realizados de nueva planta como el de Fuenterroble de Abajo. También existieron interesantes proyectos, que quedaron en el papel, para realizar puentes sobre el Águeda en el Vado de la Atalaya en 1789, en Posadillas en 1790 o en el sitio de Cabeza Gorda en 1791. Los únicos proyectos materializados fueron el del Puente Mayor de Ciudad Rodrigo y el de los llamados puentes de Castillejo. Sobre este tema vid. E. AZOFRA Y Ma. N. RupÉreZ Almajano, "Los puentes del camino de Ciudad Rodrigo a Salamanca en el siglo XVIII: realizaciones y proyectos", Puentes singulares de la provincia de Salamanca, Salamanca, 2004, pp. 87-104. 
de 1781 , teniendo lugar la primera junta pública el 5 de enero de $1782^{8}$. Esta Sociedad, como argumentaba Simón Rodríguez Laso, primer corresponsal de Antonio Ponz en Miróbriga, se dedicó con mucho celo en varios objetos del bien público, atendiendo al mejor cultivo de sus tierras, a establecer manufacturas, al descubrimiento de minas y canteras, y ha establecido una escuela de dibujo ${ }^{9}$. Y entre los miembros fundadores de esta sociedad, integrantes del selecto grupo de ilustrados mirobrigenses, cabe destacar a dos eclesiásticos, el citado Simón Rodríguez Laso (dignidad de maestrescuela de la catedral mirobrigense, primer secretario de la Sociedad de Amigos y posteriormente nombrado rector del Colegio Español de la Universidad de Bolonia), y Ramón Pasqual Díez, prebendado de la catedral ${ }^{10}$, y a don Luis de Nieulant, Teniente General de los Reales Ejércitos y Gobernador Político y Militar de la plaza de Ciudad Rodrigo y primer director de la Sociedad de Amigos. Al panorama descrito se debe de añadir el hecho de que históricamente, y por supuesto durante la segunda mitad del siglo XVIII, Ciudad Rodrigo une a su función estratégico-militar y religiosa, la de ser una pequeña capital episcopal que vive un momento de gran esplendor con Cayetano Cuadrillero y Mota (1724-1800), uno de los más destacados y más inquietos obispos que han pasado por la diócesis civitatense,

-

${ }^{8}$ Sobre este tema vid. P. Y J. DEMERSON, "La Sociedad Económica de Amigos del País de Ciudad Rodrigo", Cuadernos de Historia Moderna y Contemporánea, $\mathrm{n}^{\circ}$ 3, 1982, pp. 35-59.

${ }^{9}$ A. PonZ, Viage de España, t. XII, Madrid, $1788\left(2^{\mathrm{a}}\right.$ ed. corregida y aumentada), p. 338.

${ }^{10}$ Llegado a Ciudad Rodrigo como mayordomo en el séquito del obispo Cuadrillero y Mota, acerca de la atractiva figura de Ramón Pasqual Díez (1743-1815), el gran difusor del arte de hacer el estuco jaspeado en la España a finales del siglo XVIII, materia en la que llegó a ejercer su magisterio durante varios cursos en la Real Academia de Bellas de San Fernando, de la que fue nombrado académico honorario el 2 de marzo de 1788 y posteriormente Caballero de la Orden de Carlos III, puede consultarse M. HERNÁNDEZ Vegas, Ciudad Rodrigo. La Catedral y la Ciudad, Salamanca, s. a., ¿1935?, Ed. facs., Salamanca, 1982 (citamos por esta edición), t. II, pp. 299-307; J. R. NIETO GONZÁLEZ, "Ramón Pasqual Díez y su obra teórica", IV Simpósio LusoEspanhol de História da Arte. Coimbra, Abril de 1987, Coimbra, 1988, pp. 105-113; IDEM, "El tratadista don Ramón Pasqual Díez", El arte de hacer el estuco jaspeado o de imitar los jaspes a poca costa y con la mayor propiedad por Ramón Pasqual Díez, racionero de la Catedral de Ciudad Rodrigo, Madrid, 1785, Valladolid, 1988, pp.13-47. En esta obra también se recoge un facsímil del tratado del racionero mirobrigense, pp. 67-134, un pequeño libro de 54 páginas más un prólogo e índice sin paginar, que no incluía láminas ni dibujos. cuyos destinos rigió entre 1763 y 1777 , año en el que fue promovido al obispado de León ${ }^{11}$. Y fruto de esas inquietudes, teñidas en gran medida de un claro espíritu ilustrado, el prelado promovió en la ciudad, otro tanto hará en la diócesis, la construcción y la renovación de algunos de sus edificios más significativos, encomendando la realización de todos esos proyectos a su arquitecto de confianza, Juan de Sagarbinaga.

En este ambiente económico y cultural que hemos descrito se enmarca tanto el proceso de revitalización de la platería mirobrigense como el de adquisición de la mayoría de piezas de procedencia foránea que todavía hoy conserva, y entre ellas lógicamente las originarias de talleres portugueses. No obstante no creemos que ese contexto favorable sea el único parámetro a considerar para explicar tal concentración de piezas portuguesas y en la zona geográfica reseñada. Probablemente otro de los factores a tener en cuenta sea el del momento de esplendor por el que atravesaba la orfebrería lusa, como se pone de manifiesto en la magnífica calidad artística de las piezas de esos años que se han conservado de los centros plateriles más importantes de Portugal, y en un momento en el que ya había transcurrido más de medio siglo sin guerra en la "raya", circunstancia que, sin duda, pudo favorecer la reactivación de unas relaciones comerciales que, por otra parte, y al igual que debió ocurrir con las artísticas, sobre las que volveremos más tarde, no creemos que se vieran interrumpidas de forma total en ningún momento. En este caso quizás la vía más lógica de llegada de las piezas fuese a través de las ferias, principal camino para la recepción de estos objetos, resultando muy tentador pensar en las de Ciudad Rodrigo, si bien consideramos que de haber sido la vieja Miróbriga el punto de compra-venta de las piezas éstas deberían haber estado más extendidas por toda la diócesis rodericense. Por todo ello, pero sin descartar del todo esa posibilidad, acaso debamos pensar en otro centro ferial o urbano de cierta importancia

\section{-}

11 Tomó posesión de la sede civitatense el 30 de agosto de 1763 e hizo su entrada solemne en Ciudad Rodrigo el 14 de octubre. Un buen semblante sobre este prelado en J. Ma BLANCO HERNÁNDEZ, "La fundación del Seminario Conciliar de San Cayetano de Ciudad Rodrigo", Boletín del Obispado de Ciudad Rodrigo, Salamanca, 1970, pp. 42-46. La biografía más completa en J. EGUIAGARAY y PALLARES, $E l$ Ilmo. Sr. Obispo D. Cayetano Antonio Cuadrillero y el Hospicio de León, León, 1950. 
sito allende la frontera y más o menos equidistante de las poblaciones de la diócesis ya reseñadas, como podrían ser Guarda, Viseu, Aveiro o seguramente Oporto, sobre todo si tenemos en cuenta que todas las piezas punzonadas proceden de los talleres de la ciudad donde desemboca el Duero y de dos centros obradores muy cercanos a ella, el de Braga y el de Guimaraes. $\mathrm{Y}$ antes de abandonar este ámbito de las transacciones mercantiles nos gustaría apuntar otra hipótesis de trabajo, aunque de difícil respuesta por el momento, la de la posibilidad de que existieran orives portugueses, al igual que por las mismas fechas los hubo en la platería cordobesa $^{12}$, que desempeñaran la función de corredor comercial de la platería, dedicándose en este caso a cruzar de norte a sur la diócesis civitatense.

Por otra parte tampoco creemos que se deban descartar por el momento otras posibles vías de llegada para estas piezas como, por ejemplo, pudieran ser los contactos profesionales entre artistas portugueses y mirobrigenses, aspecto para el que se conocen ejemplos documentados desde finales del siglo XVI ${ }^{13}$, o incluso el establecimiento de algún orive o artífice luso en Ciudad Rodrigo o en su diócesis con motivo de llevar a cabo algún encargo de interés $^{14}$. Así, por ejemplo, en 1833 Juan Antonio Pereira, platero de origen portugués, natural de Braga y residente en Ciudad Rodrigo, alcanzó el grado de maestro en la cofradía de plateros de San Eloy de Salamanca ${ }^{15}$.

\section{-}

12 M. PÉREZ GRANDE, "La platería cordobesa y los corredores de comercio del último cuarto del siglo XVIII", IV Congreso Nacional de Historia del Arte. Tipologías, talleres y punzones de la orfebrería española (Zaragoza, 1982), Zaragoza, 1984, pp. 273-289.

${ }^{13}$ M. PÉREZ HERNÁNDEZ, “Relaciones...”, pp. 57-58.

${ }^{14}$ Por ejemplo esto es lo que ocurrió con el arquitecto portugués Manuel Méndez. Si bien la primera noticia que de él tenemos le sitúa trazando la iglesia del convento de la Pasión de San Felices de los Gallegos, obra materializada entre 1766 y 1768 , unos años más tarde, en 1774 y 1775 , ya aparece como vecino de Ciudad Rodrigo donde, además de trazar y dirigir obras de cierto interés, tanto religiosas como públicas, ocupará el cargo de Maestro en las Reales Obras de Fortificación.

${ }^{15}$ Ibidem, pp. 64. Tal vez este Juan Antonio Pereira tenga alguna relación familiar con el maestro o profesor de arquitectura José Francisco Pereira, hasta ahora de origen desconocido, pero que desarrolla una intensa actividad profesional, en unos casos como tracista y en otros como mero ejecutor material de los proyectos redactados por otros maestros, tanto en Ciudad Rodrigo (donde llegó a ser veedor de obras, de teja y ladrillo junto a Carlos de Almeida en
Por último, cabe sopesar incluso otro factor que pudo resultar determinante en la llegada de esas piezas, el gusto estético del comitente, sobre todo para los ejemplares más trabajados y decorados como pueden ser los cálices de Lumbrales, San Felices de los Gallegos y Fuentes de Oñoro, o la custodia de Villar de Ciervo (respectivamente lámina 7,1 y 2; lámina 8,1 ). En este sentido no se debe olvidar que en Ciudad Rodrigo se apostó en el último tercio del siglo XVIII por un gusto artístico de tono clasicista, fundamentalmente en el campo de la arquitectura y de la orfebrería, como hemos planteado con anterioridad, que quizás en otros ámbitos de la diócesis aún podía no resultar tan atractivo, haciéndose entonces necesario acudir a otros centros, que además en este caso resultaban ser los más cercanos, donde se seguían asumiendo gustos más tradicionales o retardatarios pero con los que probablemente los comitentes se sentían más identificados.

De la veintena de piezas que componen el conjunto de orfebrería portuguesa encontrado en la diócesis civitatense, y de cuya distribución geográfica ya se ha hablado en el presente trabajo, excepción hecha de la conocidísima custodia templete que sirvió en la catedral mirobrigense para el culto de las Cuarenta Horas ${ }^{16}$, así como un cáliz perteneciente también al tesoro catedralicio (lámina 3,1), una de hacia el 1600 y otra de la primera mitad del siglo XVII, las restantes son piezas pertenecientes a la decimoctava centuria y primeros años de la siguiente, de estilo barroco alguna y rococó o de transición al neoclasicismo la mayoría. En todo caso unas y otras constituyen un magnífico ejemplo de la difusión que en España tuvieron tanto algunos de los principales centros lusos de producción como de algunos de los modelos que en ellos se acuñaron. De hecho, las semejanzas entre varias de las obras que aquí publicamos y otras exhibidas en museos lusitanos inciden en una perspectiva

1793), como en su diócesis en los últimos años del siglo XVIII, fundamentalmente desde 1788 hasta 1794, sin descartar que sea el mismo maestro José de Pereira que vuelve a aparecer informando sobre una obra en Ciudad Rodrigo en 1821.

${ }^{16}$ Una referencia explícita sobre ella aparece recogida en el inventario de alhajas de la catedral mirobrigense del año 1868, donde se lee: Otra id. (custodia) para las cuarenta horas de figura de torre $y$ de plata sobredorada. M. PÉREZ HERNÁNDEZ, "Las artes del objeto...", en E AZOFRA (Ed.) La Catedral de Ciudad Rodrigo..., p. 386 . Una bibliografía más exhaustiva sobre ella ya ha sido reseñada en la nota 2. 
no explotada suficientemente en los trabajos realizados sobre la platería portuguesa, el de la proyección de sus modelos más genuinos hacia templos de localidades situadas al otro lado de la frontera, en un momento en el que, como anteriormente ya se ha señalado, la competencia con otros centros de producción nacional (Madrid, Córdoba o Salamanca) era muy fuerte, pues atravesaban por uno de sus mejores momentos tanto en creatividad como en habilidad y en capacidad técnica de sus artífices. Precisamente han sido en algún caso esos diseños indiscutiblemente portugueses argumento suficiente para confirmar su procedencia, independientemente de que ésta pueda luego verse ratificada por los correspondientes punzones.

Será este capítulo de las marcas el primero sobre el que nos detengamos en el estudio que a partir de ahora haremos del conjunto, y es así porque de su análisis se podrá colegir, entre otras cuestiones, la diversidad de centros representados: Oporto, Braga, Lisboa y Guimaraes. Si el lugar de procedencia está resuelto para la mayoría de las piezas no podemos decir lo mismo de los autores, y no es porque nos encontremos ante marcas inéditas o desconocidas, pues todas, salvo alguna excepción a la que más adelante nos referiremos, aparecen registradas en los prontuarios de Reynaldo dos Santos e Irene Quilhó $^{17}$, o en el más reciente y completo de Fernando Moitinho ${ }^{18}$, sino porque el peculiar sistema de marcaje en Portugal, compuesto de iniciales, impide en la mayoría de los casos conocer la identidad del platero que se esconde tras ellas. Sería necesario consultar otras fuentes, principalmente de tipo documental, como archivos notariales, municipales, parroquiales o de las propias organizaciones profesionales, para resolver esta cuestión.

Oporto y Lisboa fueron los dos principales centros de producción de platería portuguesa. Del primero de ellos procede el grupo más numeroso de piezas, ocho en total, a las que podemos sumar alguna más que, aún sin punzonar, tenemos la certeza que también salieron de talleres de esa ciudad. Aunque somos conscientes de lo limitado del número de obras que aquí tratamos, y de lo extraordinario del campo de

\footnotetext{
${ }^{17}$ R. Dos SANTOS E I. Quilhó, Ourivesaria portuguesa nas coleçoes particulares. 2 vols, Lisboa, 1959.

${ }^{18}$ F. MoitinHo DE AlmeIDA, Marcas de pratas portuguesas e brasileiras (Século XV a 1887), 1995.
}

trabajo, fuera de la propia Portugal, creemos posible afirmar que en conjunto constituyen un magnífico exponente del excelente momento por el que atravesaba la orfebrería portuense del siglo XVIII, tanto por la originalidad de los diseños como por la calidad de ejecución, cualidades ambas aplicables a la mayoría de ellas. En cuanto a los punzones de Oporto, salvo el que figura en el copón de la parroquia de Villar de Ciervo (Lámina 1, 1), que parece coincidir con las variantes identificadas con los números $2 \mathrm{y}$ con las siglas P-9 de los trabajos publicados por Reynaldo dos Santos e Irene Quilhó y Fernando Moitinho, respectivamente, y que fue empleada por un contraste en activo durante la primera mitad del siglo XVIII ${ }^{19}$, las restantes (Lámina 1, 2 y 3) se asemejan a las recogidas en ambos prontuarios con los números 5,6 y 7 y $\mathrm{P}-13$ a P$17^{20}$, fechadas en el último cuarto del siglo XVIII y primeros años del XIX, cronología que encaja perfectamente con el estilo de las obras donde han aparecido.

Dos son los cálices procedentes de la ciudad de Braga, muy similares en cuanto a factura, y ambos punzonados con la misma marca nominal, por lo tanto obra del mismo platero, sin embargo la matriz empleada para imprimir la marca de localidad es distinta, correspondiendo una (Lámina 1, 4) a la variante identificada por Moitinho como B-5 o B-6, y la otra (Lámina 1,5) a la B-7, ambas utilizadas por ensayadores cuya actividad está documentada entre los últimos años del siglo XVIII y primeros del XIX ${ }^{21}$.

La pieza lisboeta del conjunto ya fue dada a conocer por nosotros en un trabajo sobre el Tesoro Sagrado de la catedral mirobrigense, se trata de un cáliz portador de una variante de localidad utilizada durante el primer cuarto del

\section{-}

19 A pesar de encontrarse parcialmente frustro parece reproducir un contorno circular lobulado con la inicial P en su interior. R. Dos SANTOS E I. Quilhó, Ourivesaria..., vol. I, p. 30. F. MoITINHO DE AlmeIDA, Marcas..., p. 188.

${ }^{20}$ Punzón rectangular con los lados verticales ligeramente cóncavos, escotadura en el horizontal inferior y remate quebrado en el superior, en el interior dispone la consabida P. R. Dos SANTOS E I. Quilhó, Ourivesaria..., vol. I, p. 30. F. MoitinHo DE AlmeidA, Marcas..., pp. 189190.

${ }^{21}$ Se trata de un sello rectangular, con la inicial B en su interior y con un remate en forma de tiara, en cuyo interior se dibuja un triángulo invertido o una cruz.. F. MOITINHO DE AlmeIDA, Marcas..., pp. 27 y 28. 
siglo XVIII (Lámina 1, 6) ${ }^{22}$. Por último, procedente de Guimaraes es la cruz procesional de La Bouza, localidad muy próxima a la frontera con Portugal, y que reproduce una tipología ampliamente difundida en la platería lusitana, siendo especialmente significativo el número de piezas semejantes a esta que se han conservado en localidades de la diócesis de BragançaMiranda. La variante de localidad (Lámina 1,7) coincide sustancialmente con alguna de las dibujadas en los citados catálogos de marcas portuguesas, concretamente una en el trabajo de Reynaldo dos Santos e Irene Quilhó ${ }^{23}$, y otra la identificada como G-5 en el de Fernando Moitinho, quien además afirma que se trata de una marca registrada en 1784 y empleada hasta 1796, durante el fielato de Manuel José de Sou$\mathrm{za}^{24}$.

Del resto de piezas que no llevan marcas, sin que ello suponga que tengamos duda alguna sobre su procedencia portuguesa, que viene avalada bien por reproducir modelos característicos de aquel país, bien porque técnica y plásticamente están próximas a obras cuya procedencia lusa está sobradamente contrastada, proponemos para cuatro de ellas (los dos cálices de San Felices de los Gallegos, uno del tesoro de la catedral y la custodia de Villar de Ciervo) un origen portuense. La ausencia de marcas en las otras dos (la citada custodia templete de la catedral y el otro cáliz del tesoro catedralicio), debido posiblemente a la inexistencia de marcadores de plata en Portugal desde el último cuarto del siglo XVI hasta finales del XVII, unido a que ambas reproducen modelos ampliamente difundidos por toda la geografía lusa, como se comprueba con la serie de piezas similares expuestas en varios museos, nos impide pronunciarnos sobre su centro de procedencia.

Por lo que se refiere a las marcas nominales, entendemos que todas corresponden a los plateros que las fabricaron, pues los marca-

-

22 M. PÉREZ HERnÁNDEZ, “Las artes del objeto...”, en E Azofra (Ed.) La Catedral de Ciudad Rodrigo..., pp. 387388. Reproduce el sello un perfil lobulado que alberga en su interior la inicial "L" flanqueada por dos flores cuatripétalas.

23 Aunque parcialmente frustra, advertimos un contorno ovalado de perfil ondulado y con un remate trilobulado que en su interior alberga tres flores cuatripétalas. R. DOS SANTOS E I. QuILHÓ, Ourivesaria..., vol. I, p. 31.

${ }^{24}$ F. Moitinho DE Almeida, Marcas..., p. 58. Punzón ovalado con remate trilobulado en cuyo interior se aloja la inicial "G" rematada con tres flores de cuatro pétalos. dores y ensayadores lusos, una vez comprobada la calidad del material y que ésta se ajustaba a la exigida por la ley, se limitaron a grabar el punzón de la localidad donde ejercían el cargo, sin que nos conste que dispusieran de uno propio, como sucedía en España. Tampoco el criterio seguido en la fabricación de estos troqueles, series de iniciales, facilita la identificación del platero que se oculta tras ellas.

De las ocho piezas salidas de talleres portuenses tres, los cálices de Alberguería de Argañán, Retortillo y Villar de la Yegua presentan el punzón MG (Lámina 2, 1) ${ }^{25}$, platero cuya actividad está documentada entre los años 1768 y 1804. Los otros cuatro son creaciones de otros tantos maestros de los que, obviamente, también desconocemos su identidad, y que punzonan sus obras con MMC (Lámina 2, 2), cáliz de Lumbrales $^{26}$, JBQ (Lámina 2, 3), cáliz de Fuentes de Oñoro $^{27}$, AD (Lámina 2, 4), cáliz del convento de Porta Coeli del Zarzoso ${ }^{28}$, y C/MV (Lámina 2, 5), marca parcialmente frustra que pertenece, según Fernando Moitinho, a Manuel Vieira de Carvalho, platero portuense activo durante el primer cuarto del siglo XVIII, y que ha aparecido en un copón de la iglesia parroquial de Villar de Ciervo ${ }^{29}$. En la última de las piezas de origen

${ }^{25}$ Se trata de uno de los punzones más conocidos de la platería portuguesa de esos años, y cuya presencia ya ha sido probada en piezas encontradas en la geografía española. Recogido por R. Dos SANTOS E I. QuILHÓ, Ourivesaria..., vol. II, p. 15, punzón $\mathrm{n}^{\circ}$ 49. F. MOITINHO DE ALMEIDA, Marcas..., p. 273, Punzón P-463. Sobre las piezas encontradas en Salamanca con esta marca, M. PÉREZ HERNÁNDEZ, "Relaciones ...". IDEM, "Las artes del objeto...", en E AZOFRA (Ed.) La Catedral de Ciudad Rodrigo..., pp. 387-388.

${ }^{26}$ Recogido con el $n^{\circ} 54$, pág. 15 , en el trabajo de R. Dos SANTOS E I. QUILHÓ, Ourivesaria...; e identificado como P-484 en el prontuario de F. MOITINHO DE ALMEIDA, Marcas ..., p. 277. Esta obra ha sido expuesta en la muestra de las Edades del Hombre que bajo el título de Kyrios se está celebrando actualmente en la catedral de Ciudad Rodrigo. M. PÉREZ HERNÁNDEZ y E. AZOFRA, "Ficha n ${ }^{\circ} 109$ ”, en Catálogo Exposición "Kyrios" (Ciudad Rodrigo), Salamanca, 2006, pp. 259-260.

${ }^{27}$ F. Moitinho De Almeida, Marcas..., p. 258, Punzón P-382.

${ }^{28}$ A pesar de tratarse de una impresión defectuosa no dudamos que esa es su lectura correcta. Ya fue recogido por R. Dos SAntos E I. Quilhó, Ourivesaria..., vol. II, p. 16, Punzón $\mathrm{n}^{\circ}$ 64, y por F. Moitinho DE AlmeidA, Marcas..., p. 208, Punzón P-105.

${ }^{29}$ R. Dos SAntos E I. Quilhó, Ourivesaria..., vol. II, p. 25, Punzón n ${ }^{\circ}$ 256. F. Moitinho DE AlmeidA, Marcas..., p. 229, Punzón P-224. Esta misma marca figura en la cruz procesional de Algoso, de un modelo similar al de La Bouza (F. PEREIRA, A ourivesaria religiosa no concelho de Vimioso, Vimioso, 1997, p. 26). 
portuense, el copón de la iglesia de Coquilla de Huebra, la marca nominal está tan deteriorada que es imposible su identificación.

Las dos obras procedentes de Braga, un cáliz conservado en Alberguería de Aragañán y otro en Castillejo de Azaba, tienen el mismo punzón nominal, MG (Lámina 1, 4 y 5), inédito hasta este momento ${ }^{30}$. Se trata de un troquel con las mismas iniciales que las empleadas por un contemporáneo suyo activo en Oporto, aunque el análisis grafológico nos permite concluir que no se trata del mismo sello, y por lo tanto muy probablemente no pertenezcan a la misma persona. Tampoco ha habido mayor fortuna en la identificación del artífice lisboeta que troquela sus obras con las iniciales AS, activo en la primera mitad del siglo XVIII ${ }^{31}$. En cambio sí sabemos que el sello MFE (Lámina 1, 7), visible en la cruz parroquial de La Bouza, corresponde al registrado en el año 1796 por Manuel Ferreira Esteves $^{32}$

Por lo que al análisis estilístico de las piezas se refiere advertimos de antemano que vamos a centrarnos en las que ahora se publican por vez primera, aunque ello suponga prescindir de la que tal vez sea la más sobresaliente de todas, la custodia en forma de torre del tesoro de la catedral, para la que remitimos a la abundante bibliografía que sobre ella hemos recogido en la nota 2 de este trabajo. No obstante tampoco nos resistimos a resaltar de ella lo que consideramos como su principal activo en el contexto de este trabajo, el de constituir una réplica al otro lado de la frontera de un modelo ampliamente divulgado por toda la geografía portuguesa, y muy especialmente en los concelhos limítrofes con España.

La otra pieza cuya cronología está más próxima a la de la mencionada custodia que a las restantes, el cáliz del tesoro de la catedral de

${ }^{30}$ Del mismo autor debe ser otro cáliz de factura idéntica a los dos citados que se conserva en la localidad de Puebla de Azaba. Tal coincidencia nos confirma que nos encontramos ante un modelo que, por su modestia, fue demandado de forma habitual por templos con recursos económicos limitados.

${ }^{31}$ Sobre esta marca, M. PÉREZ HERnÁnDEZ, "Las artes del objeto...", en E. AzOFRA (Ed.), La Catedral de Ciudad Rodrigo..., pp. 387-388.

${ }^{32}$ F. Moitinho de Almeida, Marcas..., p. 70, Punzón G-70.
Ciudad Rodrigo (Lámina 3, 1) 33 $^{33}$ es una buena muestra de la llegada a Portugal de la sobriedad practicada por los plateros hispanos contemporáneos, a donde arribó de mano de los artistas españoles que a él se trasladaron aprovechando la coyuntura favorable de la unión temporal bajo el mismo cetro de los dos reinos en tiempo de los Felipes. Cierto que el cáliz mirobrigense difiere de los diseños empleados con mayor asiduidad por los plateros castellanos contemporáneos, diferencias que vienen a confirmar que los orives portugueses no se conformaron con imitar los modelos que llegaban de España sino que supieron adaptarlos a su propio gusto. Del éxito de esta propuesta dan testimonio los ejemplares que actualmente se exponen en museos portugueses como el Alberto Sampaio y Machado do Castro $^{34}$. Especialmente similar en todos es el modo de estructurar el pie, con un remate acampanado que emerge con fuerza del basamento, una solución inédita en la orfebrería hispana. Por lo que a su cronología se refiere podemos considerar que, como sucede en España, donde el modelo de cáliz seiscentista permaneció vigente incluso más allá del 1700, también este diseño fue empleado a lo largo de toda la centuria, de hecho dos de los cálices exhibidos en museos portugueses (O-27 y 6106;047) portan las armas de dos obispos que ocuparon sedes lusitanas en la primera y segunda mitad del siglo XVII, en todo caso la diferencia si se aprecia en alguna zona esa puede ser el nudo, que a medida que avanza la centuria abandona la sección ovoidal característica de las piezas de astil labradas a partir del último cuarto del siglo XVI y la sustituye por una sección periforme que acabará imponiéndose en piezas del siglo XVIII.

Para un mejor análisis del resto de cálices, los vamos a dividir en dos grupos, los que vamos a denominar cálices de ordinario, expre-

\footnotetext{
${ }^{33}$ Para la ficha técnica y comentarios sobre esta pieza remitimos al estudio que de ella se hicimos cuando analizamos el tesoro de la catedral de Ciudad Rodrigo. M. PÉREZ HERNÁNDEZ, "Las artes del objeto...", en E. AZOFRA (Ed.), La Catedral de Ciudad Rodrigo..., pp. 387-388.

${ }^{34}$ Los ejemplares similares al que comentamos corresponden a los identificados con los números de inventario $6106 ; 047$ y $6108 ; 049$. Las obras portuguesas a las que hagamos referencia a partir de ahora, salvo que se indique lo contrario, pueden verse en la Web del Instituto Portugués de Museos (IPM), con links que permiten la visualización y acceso a información sobre piezas expuestas en diferentes museos lusos: http://matriznet.ipmuseus.pt/Matriznet /MWBINT/ MWBINT00.asp
} 
sión con la que queremos identificar a los vasos usados en la liturgia diaria, se trata de obras en las que prima el carácter funcional, sobrias, $\mathrm{y}$ por lo general carentes de decoración, o limitada ésta a zonas muy concretas, como el pie. El otro grupo lo formarían los que hemos denominado cálices ricos, utilizados generalmente en las grandes festividades, son obras de ejecución más cuidada, y con un repertorio decorativo que tiende a ocupar la totalidad o la mayor parte de la superficie disponible. Estas piezas, tanto en lo estructural como en la ejecución técnica de su repertorio decorativo, sí que manifiestan claras diferencias respecto a lo que hacían sus contemporáneos españoles, no así iconográficamente, con los que están en absoluta sintonía.

En el primero de los grupos incluimos los dos ejemplares prácticamente idénticos, salidos de un mismo taller de Braga, conservados en Alberguería de Argañán (Lámina 3, 2) ${ }^{35}$ y en Castillejo de Azaba (Lámina 3, 3) 3 $^{36}$ otro también perteneciente a la parroquia de Alberguería de Argañán, procedente en este caso de Oporto (Lámina 4,1$)^{37}$, obra de un platero desconocido activo a finales del siglo XVIII, el de la iglesia de San Juan Bautista de Villar de la Yegua (Lámina 4, 2) ${ }^{38}$, los dos del tesoro de la Catedral, uno de Lisboa (Lámina 4, 3) y el otro de Oporto (Lámina 5, 1) 39 $^{39}$ y los dos copones, de Villar de Ciervo (Lámina 5, 2) ${ }^{40}$ y de Coquilla de Huebra (Lámina 5, 3) ${ }^{41}$.

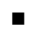

35 Ficha técnica. Plata blanca, astil y pie de bronce. Buen estado de conservación. Medidas: alto $25,5 \mathrm{~cm}$., diámetro copa $9 \mathrm{~cm}$., diámetro pie $12,5 \mathrm{~cm}$. Punzones: $\mathrm{B}$, MG, burilada.

${ }^{36}$ Ficha técnica. Copa de plata, astil y pie de bronce. Deteriorado. Medidas: alto 25,5 cm., diámetro copa 8,7 cm., diámetro pie $13 \mathrm{~cm}$. Punzones: B, MG, burilada.

${ }^{37}$ Ficha técnica. Plata blanca. Buen estado de conservación. Medidas: alto $26,5 \mathrm{~cm}$., diámetro copa $8 \mathrm{~cm}$., diámetro pie $12,5 \mathrm{~cm}$. Punzones: P, MG, burilada.

${ }^{38}$ Ficha técnica. Plata blanca. Buen estado de conservación. Medidas: alto $26,5 \mathrm{~cm}$., diámetro copa $8,4 \mathrm{~cm}$., diámetro pie $13 \mathrm{~cm}$. Marcas, deterioradas: P (?), MG (?), burilada.

${ }^{39}$ Para los aspectos técnicos de ambas obras remitimos a nuestro trabajo sobre el tesoro de la catedral mirobrigense. M. PÉREZ HERNÁNDEZ, "Las artes del objeto...", en E. Azofra (Ed.), La Catedral de Ciudad Rodrigo..., pp. 387388.

${ }^{40}$ Ficha técnica. Plata blanca. Buen estado de conservación. Medidas: alto $30 \mathrm{~cm}$., diámetro copa $13 \mathrm{~cm}$., diámetro pie $15 \mathrm{~cm}$. Marcas: de Oporto, y C/M.V (parcialmente frustra).

${ }^{41}$ Ficha técnica. Plata blanca. Aceptable estado de conservación. Medidas: alto $19,5 \mathrm{~cm}$., diámetro copa 7,9 cm.,
Tal vez sean los dos cálices procedentes de Braga los más simples de todo el conjunto, a la vez que los más retardatarios. Se componen de una peana circular, astil abalaustrado de tradición dieciochesca, con nudo periforme $\mathrm{y}$ copa estilizada de perfil acampanado. La variante de localidad, según ha confirmado Fernando Moitinho, fue empleada durante los años en que ejerció el fielato Francisco José de Silva, 18141829 , se trata por lo tanto de una de las muchas piezas que las iglesias se vieron en la necesidad de comprar para sustituir a los vasos sagrados que desaparecieron durante la Guerra de la Independencia $^{42}$. El otro cáliz conservado en Alberguería de Argañán, salido en este caso de talleres portuenses, define una tipología más habitual en la platería portuguesa ${ }^{43}$, especialmente por el remate de la peana, de forma troncocónica, el astil es muy similar al de los dos anteriores (el nudo está invertido) y la copa reproduce una morfología característica de la platería del último cuarto del siglo XVIII y primero del siguiente.

Semejante al anterior es el que, fabricado por el mismo platero, se conserva en Villar de la Yegua, del que se diferencia principalmente en la configuración de la peana, tanto por el mayor número de molduras cóncavo-convexas de que se compone como por el remate con que termina, cónico en el anterior, bulboso en el que ahora nos ocupa, que en todo caso no es un diseño que resulte extraño en la provincia de Salamanca, donde se conservan otras obras del mismo platero.

Los dos cálices del tesoro catedralicio, uno salido del taller lisboeta dirigido por un platero que punzona sus obras con AS (Lámina $4,3)$, y el otro suponemos que procedente de un

diámetro pie 7,7 cm. Punzones: de Oporto, otra frustra, burilada.

${ }^{42}$ Aunque no exista una plena concordancia en las fechas, suponemos que puede tratarse del cáliz adquirido por la iglesia de Alberguería. En las cuentas del ejercicio de 1811 figura un descargo de 585 reales, que tuvo de coste un cáliz de plata con su patena y cucharilla. A.D.C.R. Archivo parroquial de Alberguería de Argañán. Libro de cuentas de fábrica, 1746-1879 (Sig. 159), f. 232 vº.

${ }^{43}$ Muy similar es el inventariado como 15.18 MFTPJ del Museo de Francisco Tavares Proença Junior (http://matriznet.ipmuseus.pt/Matriznet/MWBINT/MWBIN T00.asp). La principal diferencia reside en que el cáliz conservado en Alberguería es totalmente liso, mientras que su homólogo portugués tiene decoración repujada en la moldura convexa del pie. 
taller portuense (Lámina 5,1$)^{44}$, posiblemente del regentado por el anónimo $\mathrm{MG}$, confirman la existencia en todos los periodos de obras exentas de decoración cuyo principal mérito reside en la aplicación correcta de las proporciones y en una buena ejecución técnica del torneado de la plata.

También los dos copones reproducen modelos habituales en la platería del vecino país. Su estructura general apenas difiere de la descrita en los cálices, por lo tanto las peanas pueden resolverse con más o menos molduras, o el nudo variará entre el ovoidal y el periforme. Es en el receptáculo de las Formas y en la tapa con que se cierra donde encontramos más diferencias, pero en todo caso las soluciones que en ellos vemos tampoco resultan ajenas a la platería portuguesa. El copón de Villar de Ciervo (Lámina 5, 2) opta por una copa hemiesférica y una tapadera de suave perfil cónico ${ }^{45}$, mientras el depósito del de Coquilla de Huebra (Lámina 5,3 ) es de sección bulbosa y la tapadera termina con una solución similar a la empleada en el remate del pie $^{46}$.

Un segundo grupo de obras estaría formado por aquellos cálices que estando próximos, estructuralmente hablando, a los anteriores, cubren toda o una parte importante de su superficie con una decoración repujada basada en los motivos característicos de ese momento ${ }^{47}$. Incluimos en este grupo tres cálices muy similares entre sí en sus formas, aunque diferentes en cuanto al repertorio decorativo empleado por sus artífices, procedentes todos de obradores

-

${ }^{44}$ Se trata de un diseño común en la platería portuguesa, así lo demuestra que un cáliz muy parecido a este del tesoro de la catedral civitatense se exhibe en el Museo Machado do Castro con el $\mathrm{n}^{\mathrm{o}}$ de inventario 6889;0499 (http://matriznet.ipmuseus.pt/Matriznet/MWBINT/MWBIN T00.asp).

${ }^{45}$ Una solución similar podemos ver en un copón que se exhibe en el Museo Nacional Machado do Castro ( $\mathrm{n}^{\mathrm{o}}$ de inventario 6722;O412). http://matriznet.ipmuseus.pt/ Matriznet/MWBINT/MWBINT00.asp.

${ }^{46}$ Un diseño similar presentan los copones que se conservan en el Museo de Aveiro ( $\mathrm{n}^{\circ}$ de inventario 49/D), es un copón ricamente decorado, aunque de estructura muy parecida al que ahora nos ocupa, Museo de Lamego $\left(\mathrm{n}^{\circ}\right.$ de inventario 219) y Museo Nacional de Machado do Castro ( $\mathrm{n}^{\mathrm{o}}$ de inventario 6915;O530). http://matriznet.ipmuseus.pt/ Matriznet/MWBINT/MWBINT00.asp.

${ }^{47}$ Piezas afines a las que comentamos se conservan en el Museo de Aveiro, números de inventario 26-D, 27-D y 28-D, este último con el punzón MG. http://matriznet.ipmuseus.pt/Matriznet/MWBINT/MWBINT 00. asp. portuenses, son los conservados en Fuentes de Oñoro (Lámina 6, 1) ${ }^{48}$, Retortillo (Lámina 6, $2)^{49}$ y convento franciscano de Porta Coeli del Zarzoso (Lámina 6,3$)^{50}$. Aunque difiere de los anteriores tanto en la configuración de la peana como en el repertorio decorativo integramos dentro de este grupo uno de los dos cálices pertenecientes a la iglesia de Nuestra Señora de entre dos Álamos de San Felices de los Gallegos, que aunque sin marcas no dudamos de su procedencia portuguesa $^{51}$.

Coinciden todos en la forma circular del pie y en su estructuración, con un basamento liso, y sobre él una moldura de borde convexo que en altura describe un perfil en S. El astil es, en esencia, similar al de los anteriores, una sucesión de molduras flanqueando un nudo periforme. La copa es acampanada y muy estilizada, decorada en su tercio inferior en el caso de las piezas de Fuentes de Oñoro y convento del Zarzoso, y completamente lisa en el de Retortillo.

La decoración, repujada, esgrafiada o sobrepuesta, está concentrada en la peana, formada a base de Ces contrapuestas que soportan soluciones arrocalladas, todo dispuesto de manera que refuerzan el ritmo ascensional del conjunto, y tercio inferior de la copa, donde junto a motivos de ascendencia rococó, como son la rocalla o el perfil quebrado con que remata la decoración de la subcopa, se disponen símbolos de contenido eucarístico, racimos de uvas y espigas, y pasional (lanza e hisopo, corona de espinas, y palma de martirio). Aunque en todos los casos la estética rococó es la dominante, en la subcopa del cáliz de Fuentes de Oñoro ya podemos advertir una tendencia a superar ese repertorio.

-

${ }^{48}$ Ficha técnica. Plata blanca. Buen estado de conservación. Medidas: alto $25 \mathrm{~cm}$., diámetro copa $8,8 \mathrm{~cm}$., diámetro pie $12,8 \mathrm{~cm}$. Punzones: de Oporto y JBO.

${ }^{49}$ Ficha técnica. Plata blanca. Aceptable estado de conservación. Medidas: alto 26,5 cm., diámetro copa 8,2 cm., diámetro pie $13 \mathrm{~cm}$. Punzones: de Oporto y MG, burilada.

${ }^{50}$ Ficha técnica. Plata blanca, copa dorada. Buen estado de conservación. Medidas: alto 26,5 cm., diámetro copa 8,5 $\mathrm{cm}$, diámetro pie $12,5 \mathrm{~cm}$. Punzones: de Oporto y AD.

${ }^{51}$ Ficha técnica. Plata blanca. Buen estado de conservación. Sin marcas (burilada). Medidas: alto $23,5 \mathrm{~cm}$., diámetro copa $9 \mathrm{~cm}$., diámetro pie $13 \mathrm{~cm}$. La copa, evidentemente, es reaprovechada de un cáliz anterior, lo que unido a la deficiente composición que actualmente presenta el astil le confieren un aspecto extraño y desproporcionado. 
Para el final hemos dejado las tres obras que, de cuantas componen este trabajo presentan la hechura más elaborada: los cálices de Lumbrales (Lámina 7,1$)^{52}$ y de San Felices de los Gallegos (Lámina 7, 2) ${ }^{53}$ y la custodia de Villar de Ciervo (Lámina 8,1) que, aunque sin marcas, tampoco tenemos ninguna duda sobre su procedencia $^{54}$. Común a todas es la sensibilidad con que sus autores han ejecutado el repertorio decorativo, una mezcla de técnicas (fundición, repujado, cincelado) que otorgan a las piezas unos valores plásticos y unas sensaciones táctiles totalmente diferentes a las realizadas, por ejemplo, por sus contemporáneos españoles. Se trata de obras cargadas de sentido arquitectural y escultural, hasta poder afirmar que por sí mismas constituyen un excelente ejmplo del carácter interdisciplinar de la orfebrería.

Respecto al cáliz de Lumbrales, del que desconocemos, como de todos los demás, la vía por la que ingresó en el ajuar de esta iglesia, ya expusimos en otra ocasión que reproducía un modelo que no era desconocido en la platería portuguesa, como lo demuestra los numerosos ejemplares parecidos a éste que en la actualidad se exhiben en las vitrinas de diferentes museos lusos, siendo el ejemplar salmantino uno de los más logrados de todos ${ }^{55}$. Se trata de una obra en la que confluyen la estética rococó y neoclásica, correspondiendo a la primera, además de parte del repertorio decorativo, la concepción general del conjunto y el discurso iconográfico, de evidente exaltación eucarística. Por contra, los

-

${ }^{52}$ Ficha técnica. Plata dorada. Excelente estado de conservación. Medidas: alto 28,6 cm., diámetro copa $8,4 \mathrm{~cm}$., diámetro pie $14,7 \mathrm{~cm}$. Punzones: de Oporto y MMC, burilada. Iconografía del pie: ave fénix, arca de la alianza y pelícano; copa: cruz y escalera, clavos, lanza e hisopo, martillo y tenazas. M. PÉrez Hernández y E. AZOFRA, "Ficha $\mathrm{n}^{\circ}$ 109", Catálogo de la Exposición "Kyrios" (Ciudad Rodrigo), Salamanca, 2006, pp. 259-260.

${ }^{53}$ Ficha técnica. Plata dorada. Buen estado de conservación. Medidas: alto $29 \mathrm{~cm}$., diámetro copa $9 \mathrm{~cm}$., diámetro pie $17,3 \mathrm{~cm}$. Iconografía subcopa: símbolos eucarísticos. Iconografía pie: escalera, lanza, hisopo; cruz; columna, martillo, flagelos; Santa Faz. Sin marcas.

${ }^{54}$ Ficha técnica. Bronce dorado con aplicaciones de plata. Buen estado de conservación. Medidas: alto $52 \mathrm{~cm}$., diámetro expositor $27 \mathrm{~cm}$., diámetro pie $20,5 \mathrm{~cm}$. Sin marcas.

${ }^{55}$ A los cálices que en su momento señalamos (vid. nota 36), los del Museo de Arte Antiga y Alberto Sampaio cabe sumar ahora los de los museos Grao Vasco y Aveiro, el de este último reproduce una copa idéntica a la de este de Lumbrales. http://matriznet.ipmuseus.pt/Matriznet/ MWBINT/MWBINT00.asp espejos ovalados enmarcados por Ces y las composiciones de flores de la subcopa y del nudo son signo inequívoco de la nueva sensibilidad que también empieza a llegar a la orfebrería. Especialmente original es el motivo a modo de cintas cajeadas con remate en forma de volutas que recorren radialmente la peana, y que confieren a esa parte del cáliz una plasticidad ignota en la orfebrería española contemporánea.

El segundo de los cálices pertenece a la parroquia de Nuestra Señora de entre dos Álamos de San Felices de los Gallegos, y es posiblemente el más barroco de todo el conjunto. En relación con el anterior tiene algunas notas en común, como el perfil ondulado del pie, la iconografía eucarística y cristológica, o la serie de cintas planas que recorren radialmente la peana, y que como en aquél parecen inspiradas en la arquitectura. La mayor diferencia respecto a los que hasta ahora hemos visto son el diseño del nudo y de la copa, soluciones más afines a la platería hispana contemporánea que a la lusa, lo mismo que el picado del fondo, que contrasta con la superficie pulida de los motivos ornamentales. Del repertorio decorativo destaca la presencia en el pie, dentro de un cerco vegetal, de una cruz perteneciente a la orden de San Juan, lo que posiblemente nos está indicando que esta obra no fue labrada inicialmente para el templo donde se localiza en la actualidad, a donde llegó en fecha incierta, tal vez tras los procesos desamortizadores del siglo XIX.

La custodia de Villar de Ciervo es una obra de factura impecable, obra de un artista con un excelente dominio de la técnica. El expositor, de los de tipo sol, es un buen ejemplo de la exaltación eucarística propia del siglo XVIII, con el viril rodeado de nubes, cabecitas aladas de ángeles y rayos biselados de diferente longitud. Toda la estructura descansa sobre una peana de perfil alabeado, solución que, junto a los recursos arquitectónicos de los que hace uso el autor, las ménsulas que radialmente recorren el pie, hermanan esta obra con los dos cálices analizados anteriormente ${ }^{56}$. El astil en cambio

\section{-}

${ }^{56}$ Del conjunto de recursos empleados por el autor de esta custodia varios son de uso frecuente en la platería portuguesa, véase sino las coincidencias con la custodia de Parada (F. PIRES PEREIRA, Ourivesaria religiosa concelho de Alfândega da Fé, 1994, p. 46). Aunque ambas difieren en la configuración del pie, el uso de mensulones con cabecitas aladas de ángeles en su frente, y las cabecitas fundidas de querubines distribuidas por las diferentes partes del astil, 
ofrece soluciones diferentes a las vistas con anterioridad, sobre todo por la forma del nudo, periforme, cierto que tampoco se trata de un diseño extraño a la platería portuguesa ${ }^{57}$. Pero es, sin duda, en el repertorio decorativo donde el autor de esta obra demuestra su profundo conocimiento de la estética rococó. A lo ya comentado de la decoración del expositor hay que añadir la serie de espejos ovalados enmarcados por soluciones arrocalladas de la peana. Junto a la ejecución técnica también cabe destacar en esta obra el excelente equilibrio cromático logrado por medio de la combinación del dorado del bronce con la plata en su color, empleada esta última en los elementos fundidos y en las aplicaciones que rodean el viril.

Para el final hemos dejado otra de las obras que mejor puede encarnar las dos cuestiones en las que en este trabajo hemos intentado profundizar, la de la presencia de piezas portuguesas en territorio español y que en esencia reproducen esterotipos de la orfebrería del vecino país, la cruz procesional de la localidad fronteriza de La Bouza (Lámina 8,2$)^{58}$. Se trata de una pieza de dimensiones modestas, de factura sobria y con la decoración restringida a la macolla. Es una cruz latina, de brazos cilíndricos, en cuyo anverso lleva la correspondiente imagen del Crucificado. Reproduce, sin duda, el modelo más habitual de cruz procesional en la platería portuguesa de la segunda mitad del siglo XVIII, que cuenta con ejemplares distribuidos por la práctica totalidad de su geografía, y de manera muy especial en algunos Concelhos de la diócesis de Bragança-Miranda, desde donde pudo llegar a esta localidad salmantina ${ }^{59}$ junto a la combinación cromática del expositor, son notas comunes a ambas.

${ }^{57}$ Un nudo parecido podemos ver en una custodia que se expone en la Casa Museo Dr. Anastasio Gonçalves, obra del tercer cuarto del siglo XVIII. http://matriznet. ipmuseus.pt/Matriznet/MWBINT/MWBINT00.asp
58 Ficha técnica. Plata blanca. Medidas: alto $62 \mathrm{~cm}$., brazo transversal 28,5 cm. Marcas: G, MFE, Burilada.

${ }^{59}$ Ejemplares parecidos al que ahora publicamos se conservan en las iglesias de las localidades de Penas Roias, Prado Gatao, Algoso, Campo da Viboras, Aguas Vivas, Especiosa, Brunhoso... F. PIRES PereirA, A ourivesaria religiosa...; A. RODRIGUES MOURINHO, "A ourivesaria", en Catálogo de la Exposición Comeoraçoes jubilares dos 150 anos da diocese de Bragança-Miranda, 1996. 


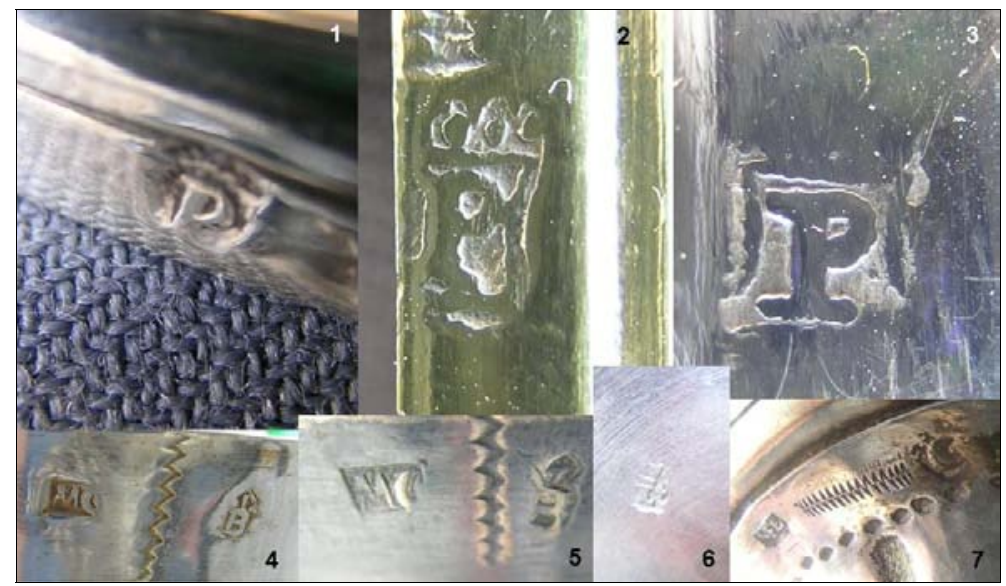

- Lám. 1. Punzones de localidad. 1, 2 y 3 de Oporto. 4 y 5 de Braga. 6 de Lisboa. 7 de Guimaraes.

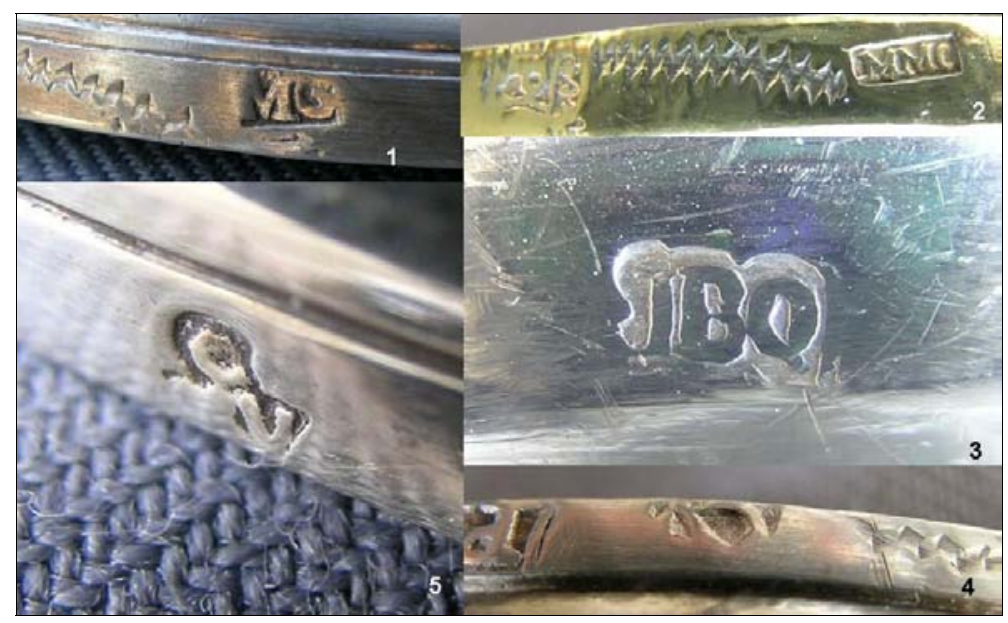

- Lám. 2. Punzones de plateros.

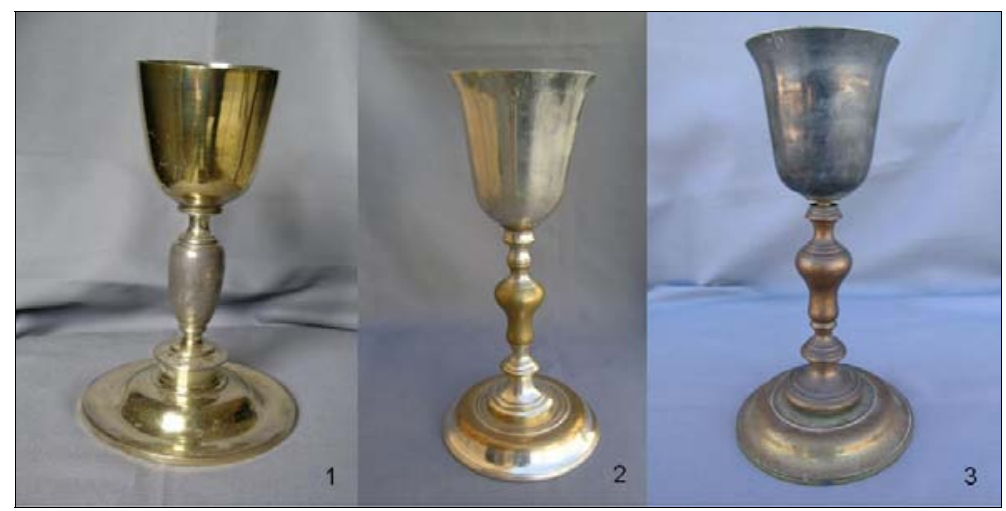

• Lám. 3. 1 Cáliz del tesoro de la Catedral de Ciudad Rodrigo. 2 Cáliz de Alberguería de Argañán. 3 Cáliz de Castillejo de Azaba. 


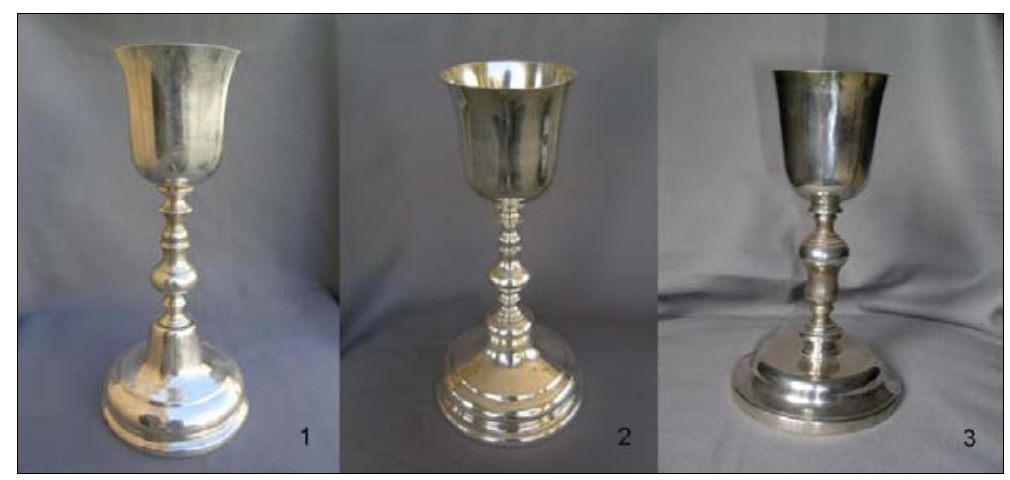

- Lám. 4. 1 Cáliz de Alberguería de Argañán. 2 Cáliz de Villar de la Yegua. 3 Cáliz del tesoro de la Catedral de Ciudad Rodrigo.

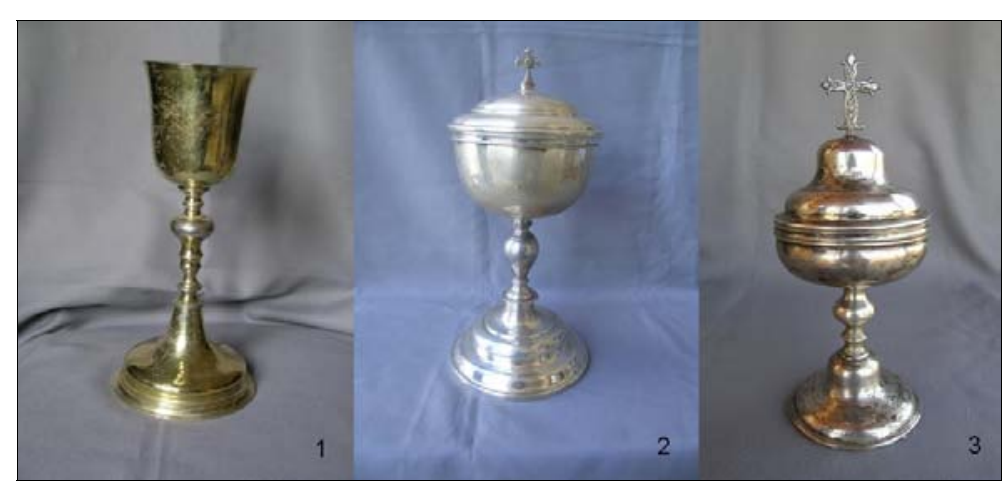

- Lám. 5. 1 Cáliz del tesoro de la Catedral de Ciudad Rodrigo. 2 Copón de Villar de Ciervo. 3 Copón de Coquilla de Huebra.

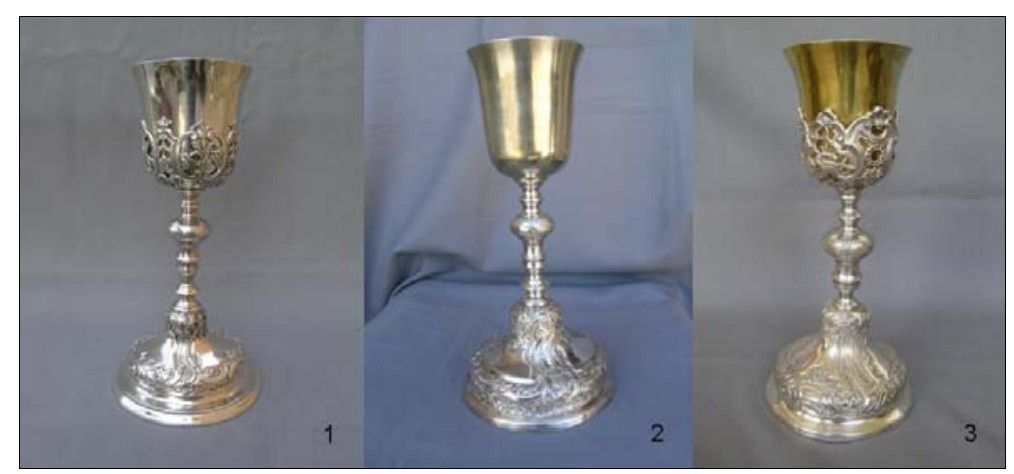

- Lám. 6. 1 Cáliz de Fuentes de Oñoro. 2 Cáliz de Retortillo. 3 Cáliz del convento del Zarzoso. 


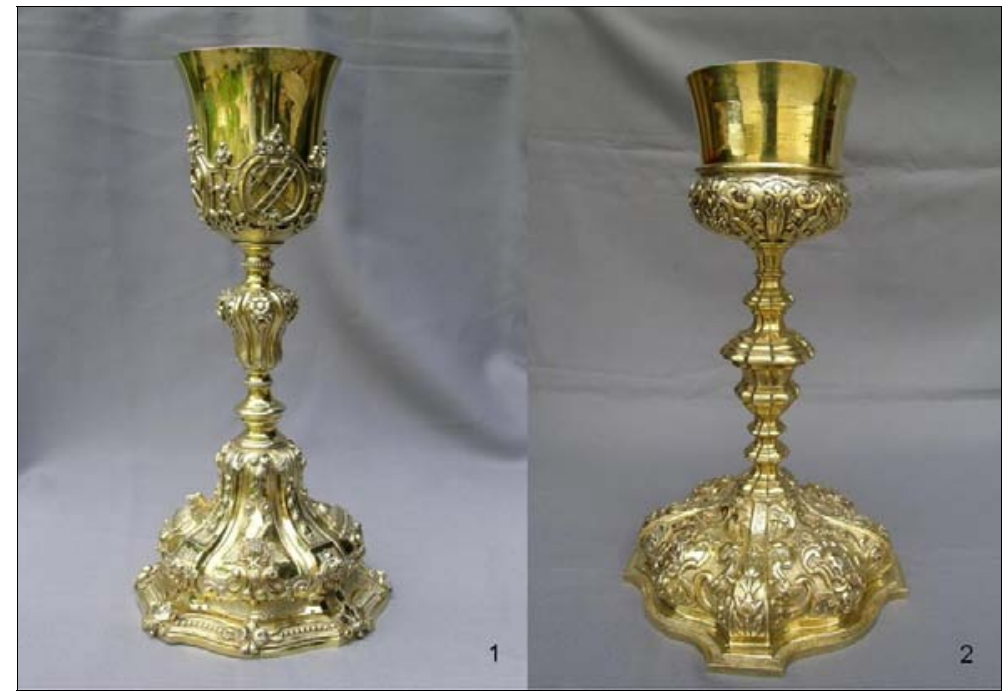

- Lám. 7. 1 Cáliz de Lumbrales. 2 Cáliz de San Felices de los Gallegos.

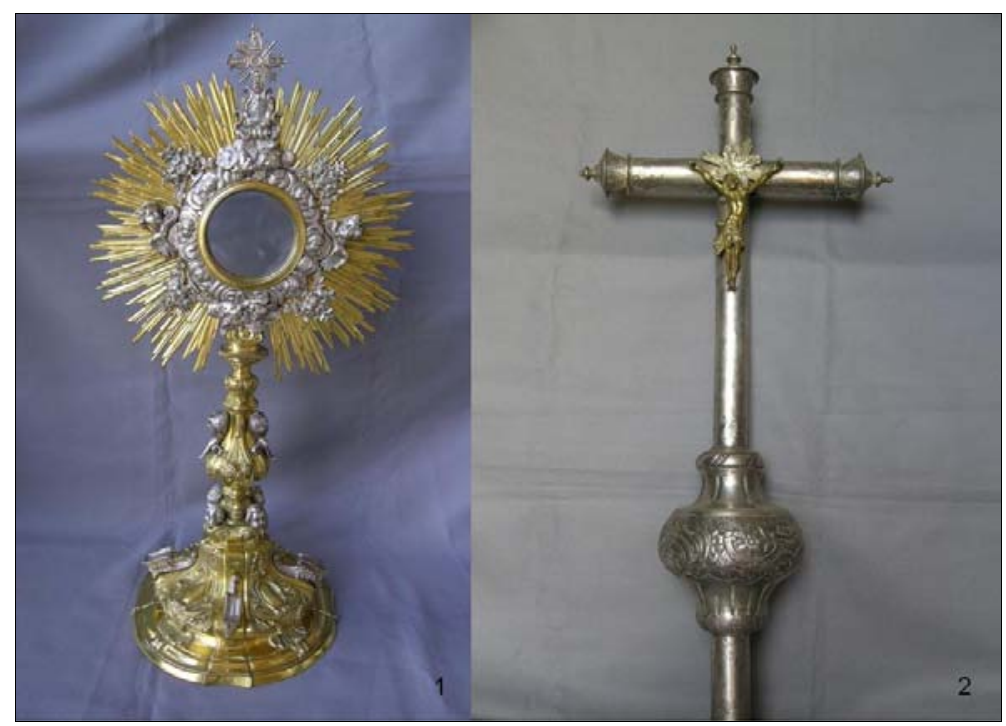

- Lám. 8. 1 Custodia de Villar de Ciervo. 2 Cruz parroquial de La Bouza. 